Assessment

\title{
Cross-cultural adaptation and validation of the health literacy assessment tool METER in the Portuguese adult population
}

\author{
Dagmara Paiva a,b,c $^{\mathrm{a}}$, Susana Silva ${ }^{\mathrm{a}, \mathrm{b}}$, Milton Severo ${ }^{\mathrm{a}, \mathrm{b}}$, Pedro Ferreira ${ }^{\mathrm{d}}$, \\ Osvaldo Santos ${ }^{\mathrm{e}}$, Nuno Lunet ${ }^{\mathrm{a}, \mathrm{b}}$, Ana Azevedo ${ }^{\mathrm{a}, \mathrm{b}, *}$ \\ a Department of Clinical Epidemiology, Predictive Medicine and Public Health, University of Porto Medical School, Porto, Portugal \\ ${ }^{\mathrm{b}}$ Institute of Public Health of the University of Porto (ISPUP), Porto, Portugal \\ ${ }^{\mathrm{c}}$ Monte Murado Health Family Unit, Vila Nova de Gaia, Portugal \\ ${ }^{\mathrm{d}}$ Institute of Social Sciences, University of Lisbon, Lisbon, Portugal \\ ${ }^{\mathrm{e}}$ Institute of Preventive Medicine, Faculty of Medicine of Lisbon, Lisbon, Portugal
}

\section{A R T I C L E I N F O}

\section{Article history:}

Received 27 January 2014

Received in revised form 20 May 2014

Accepted 13 July 2014

\section{Keywords:}

Health literacy

METER

Validation studies

\begin{abstract}
A B S T R A C T
Objective: We aimed to culturally adapt and validate METER in the Portuguese population, and to define cut-off values for adequate health literacy.

Methods: We used the standard procedure for the adaptation of the words and surveyed health professionals to select the non-words. The instrument was administered to a total sample of 249 participants and retested in a sub-sample of 45 after three months. Cut-offs were defined using the modified Angoff procedure. Construct validity was assessed through association with educational attainment and health-related occupation.

Results: Exploratory factor analysis revealed two dimensions of the instrument, one for words and another for non-words. METER showed a high degree of internal consistency, and acceptable test-retest reliability. Adequate health literacy was defined as scoring at least 35/40 in words and 18/30 in nonwords. Physicians scored higher than any other group, followed by health researchers, researchers from other areas and by people with progressively lower levels of education $(p<0.001)$.

Conclusion: We culturally adapted a brief and simple instrument for health literacy assessment, and showed it was valid and reliable.

Practice implications: The Portuguese version of METER can be used to assess health literacy in Portuguese adults and to explore associations with health outcomes.
\end{abstract}

(c) 2014 Elsevier Ireland Ltd. All rights reserved.

\section{Introduction}

Individual health literacy is the degree to which individuals have the capacity to obtain, process, and understand basic health information and services needed to make appropriate health decisions [1]. Inadequate health literacy is more prevalent among the elderly, those with lower levels of educational attainment [2] and with chronic disease [3]. It is associated with poorer selfmanagement skills, less successful navigation of the healthcare system, higher morbidity and mortality [3-6].

\footnotetext{
* Corresponding author at: Departamento de Epidemiologia Clínica, Medicina Preditiva e Saúde Pública, Faculdade de Medicina da Universidade do Porto, Alameda Prof. Hernâni Monteiro, 4200-319 Porto, Portugal. Tel.: +351 225513652 Fax: +351225513653.

E-mail address: anazev@med.up.pt (A. Azevedo).
}

The European Health Literacy Survey 2011 [7], conducted in eight European countries (Austria, Bulgaria, Germany, Greece, Ireland, the Netherlands, Poland, and Spain) found that only between $36.7 \%$ (in Spain) to $76.3 \%$ of the population (in the Netherlands) had adequate health literacy, as assessed by the Newest Vital Sign [8]. In Portugal, although health literacy has started to appear in the national political agenda [9], there are no published studies on the prevalence of adequate health literacy.

Health literacy is commonly measured using instruments based on word recognition or pronunciation: Medical Term Recognition Test (METER) [10], Rapid Estimate of Adult Literacy in Medicine (REALM) [11], Short Assessment of Health Literacy for Spanishspeaking Adults (SAHLSA) [12], Medical Terminology Achievement Reading Test (MART) [13]; or reading comprehension and numeracy: Newest Vital Sign (NVS) [8], Test of Functional Health Literacy in Adults (TOFHLA) [14]. Most instruments were initially developed in English or Spanish and are being adapted worldwide 
[15-19]. Word pronunciation-based instruments perform well in English but have failed adaptation to languages with very high letter to sound correspondence (such as Spanish, Portuguese and Korean) because they are unable to discriminate between health literacy and ability to read $[12,16,20]$. METER is based on word/ non-word recognition and is open-use, very brief, and selfadministered, which means it can be added to a form or questionnaire without increasing participant burden considerably. We aimed to culturally adapt and validate METER in the Portuguese population, and to define cut-off values for adequate health literacy.

\section{Methods}

\subsection{Original instrument}

METER is an English language open use instrument based on REALM, consisting of a list of 40 medical words and 30 made-up non-words that intuitively sound like real medical terms. It is selfadministered and it takes on average two minutes to complete. The participants are requested to mark only the words they are sure to be actual words. The score is calculated as the sum of all the correct words marked. The original METER performance cut-off points defined by the authors were $0-20$ for low, 21-34 for marginal and 35-40 for functional health literacy levels [10].

\subsection{Cross-cultural adaptation}

We used the standard procedure for word adaptation [21]. An expert committee (with backgrounds in Family Medicine, Internal Medicine, Pharmacy, Psychology, and Sociology) ensured conceptual and item equivalence. Afterwards, two native Portuguese speakers proficiently fluent in English translated METER independently and merged the translations into a single Portuguese version. Next, two native English speakers, proficient in Portuguese, independently back-translated this version. They were unaware of the purpose of the instrument and had not seen the original version. The translators arrived at a consensus backtranslated version, which was then revised and compared to the original by the committee, resolving any discrepancies between the two versions.

For the non-words, we surveyed 25 health professionals to identify common misspellings and build up constructions based on real medical terms, 30 of which were selected by the research team for inclusion in the instrument. The selection criteria were to avoid redundancy and to maximize diversity of conceptual areas.

This version was pre-tested in a small group of six lay people and the instructions wording was adjusted for the sake of clarity.

\subsection{Sample and recruitment}

The adapted version of the test was administered to a convenience sample of 249 people from several heterogeneous groups: physicians (from public hospitals and primary care health centers), health researchers (from a research institute), researchers from areas unrelated to health (from an engineering faculty), and general population (from a primary care health center). In the absence of prevalence data of inadequate health literacy in this population, the sample size was estimated based on other validation studies $[8,11,12]$. To assess construct validity we assumed that physicians would score highest on health literacy tests, followed by health researchers, people with a similar academic degree in areas unrelated to health, and by people with progressively lower levels of education attainment.

Eligibility criteria for the participants were age over 18 years and ability to speak and read Portuguese. Potential participants with impaired vision were excluded. The instrument was readministered to a convenience group ( 45 health researchers) after a three-month interval to assess test-retest reliability. This rather long test-retest interval of time aimed to reduce mnesic/learning bias.

The present investigation was carried out in accordance with the Code of Ethics of the Declaration of Helsinki and approved by the Ethics Committee of Centro Hospitalar de São João and the National Committee for Data Protection. Each participant provided written informed consent.

\subsection{Cut-off definition}

In the absence of a gold standard, cut-offs were defined using the modified Angoff procedure, a content-procedure method extensively applied for establishing absolute assessment criteria [22]. It is based on expert judgment of minimal competence of marginally competent individuals: a panel of judges trained in the use of the method discusses and agrees on the characteristics of a examinee scoring "borderline" for adequate health literacy and independently classifies each item according to the question "Can a person with minimal competence answer the item correctly?", given a three-choice option of "yes", "no" or "don't know". An average of the scores of the judges is calculated to provide a passing score (the cut-off). The judges are allowed to review and discuss the initial scores and are given the option to independently alter their own classification if they wish to; this strategy usually does not change cut-offs meaningfully but reduces variability between judges [23]. The panel comprised six health literacy experts (with backgrounds in Family Medicine, Internal Medicine, Pharmacy, Psychology, and Sociology).

We used this method to dichotomize health literacy levels into adequate or inadequate in order to help guide decisions to tailor patient education and communication interventions to the patients' needs, both in future research and clinical practice.

\subsection{Statistical analysis}

Exploratory factor analysis was performed on the 70 items to evaluate homogeneity (i.e., to confirm there was a single latent variable measuring word recognition) and Cronbach's alpha was used to measure internal consistency. An item was considered to load in a determined factor when it showed an absolute factor loading higher than 0.4 .

Physicians were excluded from these analyses, since they are not targets of the instrument. The global goodness of fit of the underlying model was evaluated using the comparative fit index (CFI), recommended for sample sizes below 250 [24].

Logistic regression was used to compare the prevalence of adequate health literacy across validation groups, adjusting for age.

Test-retest reliability was assessed using the standard error of measurement and respective two-way mixed intra-class correlation coefficient single-measure (ICC).

Exploratory factor analysis models were fitted using MPlus (V.5.2; Muthen \& Muthen, Los Angeles, California, USA). All other statistical analyses were performed using Stata version 11.1 for Windows (StataCorp LP, College Station, TX).

\section{Results}

Demographic characteristics of the sample by validation group are summarized in Table 1 . Women made up the majority of respondents in all validation groups (56.6\%), except for the group of researchers in areas unrelated to health (12.0\%). Less educated people were older. 
Table 1

Demographic characteristics of the sample by validation group.

\begin{tabular}{lllr}
\hline Validation group & $n$ & $\begin{array}{l}\text { Age in years, } \\
\text { mean (SD) }\end{array}$ & Women, $n(\%)$ \\
\hline $\begin{array}{l}\text { Physicians } \\
\text { Health researchers }\end{array}$ & 53 & $32.3(7.1)$ & $34(64.2)$ \\
$\begin{array}{l}\text { Other researchers } \\
\text { General population }\end{array}$ & 50 & $43.8(13.0)$ & $67(82.2)$ \\
$\quad$ College education & 18 & $41.6(13.7)$ & $11(61.1)$ \\
12th grade & 15 & $34.8(11.1)$ & $8(53.3)$ \\
9th-11th grade & 22 & $38.5(12.4)$ & $14(63.6)$ \\
5th-8th grade & 17 & $41.4(14.0)$ & $10(58.8)$ \\
$\quad \leq 4$ th grade & 29 & $61.1(9.2)$ & $21(72.4)$ \\
\hline
\end{tabular}

SD-standard deviation.

\subsection{Exploratory factor analysis}

The scree plot curve inflected at the second component, revealing two underlying dimensions of the instrument (Fig. 1). Exploratory factor analysis confirmed these two dimensions, with almost all the items representing real words being included in the first dimension, and all the non-words in the second (Table 2). The CFI of the model improved from 0.83 in the uni-dimensional model to 0.93 with the two dimensions.

Fig. 2 depicts the plot of the percentage of correctly marked words against the percentage of non-words that were correctly not selected. The former ranged from 15 to $100 \%$, whereas the latter from 45 to $100 \%$. These two dimensions were poorly correlated $(r=0.22)$ and three patterns emerged, visually: a group of people scoring over two-thirds in both; a group scoring lower in the identification of real words and a group scoring lower in nonwords. No one correctly identified less than two-thirds of both words and non-words.

\subsection{Reliability}

METER showed a high degree of reliability, with a Cronbach's alpha of 0.92 for the first dimension and 0.83 for the second. In the retest study after three months, the standard error of measurement was 1.54 for the words (ICC 0.49 ) and 0.82 for the non-words (ICC 0.61).

\subsection{Cut-off definition}

The final cut-offs defined by the judging panel using the Angoff method were 35 correct answers in the words subscale and 18 correct answers in the non-words subscale. The review, discussion and experts' independent adjustment of the initial scores kept cutoffs roughly unchanged (the cut-off for non-words increased by one point in the second round and the cut-off for words remained

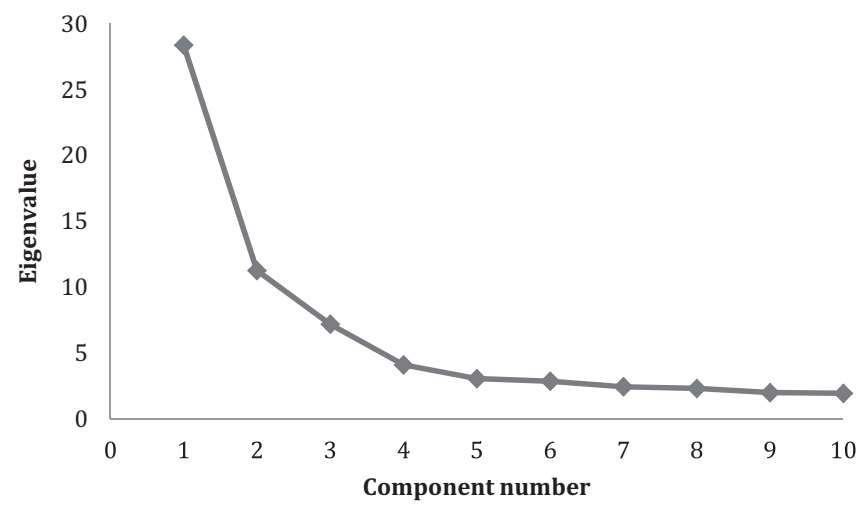

Fig. 1. Scree plot of eigenvalues after exploratory factor analysis. constant) and reduced the variability between judges (the standard deviations decreased from 3.45 to 1.21 and from 2.71 to 1.50 , for non-words and words, respectively).

We used these cut-offs to categorize health literacy as inadequate or adequate; adequate was defined as scoring at least the cut-off value in both words and non-words, i.e. $\geq 35 / 40$ and $\geq 18 / 30$, respectively.

\subsection{Validity}

Physicians scored higher than any other group, followed by health researchers, non-health researchers and by people with progressively lower levels of education (Fig. 3). The age-adjusted prevalence of adequate health literacy increased consistently across validation groups $(\mathrm{OR}=2.79$ for physicians, compared to people with education attainment below the fourth grade; $p$ for trend $<0.001$ ).

\section{Discussion and conclusion}

\subsection{Discussion}

We culturally adapted a health literacy instrument that is brief and simple, and showed it was valid and reliable. This instrument can be used to assess health literacy levels and to sort between adequate and inadequate health literacy. We propose that words and non-words should be treated as different sub-scales with separate scoring.

Exploratory factor analysis revealed two dimensions of the instrument, one for words and another for non-words, implying that some individuals scored high in one dimension and low in the other. Because of the design of the original instrument, in which the participants are required to mark only the words they are sure to be actual words and not individually mark each item as true or false, the non-word items likely measure more than merely word recognition. The results suggest that this dimension also measures risk aversion, i.e. individuals more averse to error mark less words and non-words, thus scoring lower in the words sub-scale and higher in the non-word subscale; the opposite applies to less cautious individuals. The fact that no one scored very low in both dimensions supports this interpretation. With the original scoring instructions (total score as the sum of all the correct words marked), in the unlikely event that a participant marked all of the items, he/she would achieve the maximum score, even though that would not correspond to adequate health literacy. Therefore, scoring the two dimensions independently and then combining the performance on both sub-scales will reduce the misclassification of individuals with inadequate health literacy.

The rare exceptions to the perfect correspondence between words and non-words and each of the two dimensions were items 4 (a word that could fit in either dimension), item 37 (a non-word that could fit in either dimension), and item 47 (a word that does not fit in either dimension). Only one individual neglected to correctly mark item 4 as a word, and this might have misestimated the correlation due to ceiling effects, loading the item in both dimensions. Item 37 is one of the good examples of the effect of the small but significant correlation between the first and second dimensions - several items partially cross-loaded in both (as can be observed by the small factor loading differences between factors one and two). Item 47 is "impetigo", a contagious skin infection which causes sores and blisters, and relatively unfamiliar to lay people. Very few non-physicians correctly selected this word and this could explain why it does not fit in either dimension; it seems to be almost exclusively recognized by health professionals. Our finding is consistent with the word frequency effect in word 
Table 2

Correct answers per item in words and non-words, and standardized factor loadings for one and two factors in exploratory factor analysis.

\begin{tabular}{|c|c|c|c|c|c|c|}
\hline & & & \multirow[t]{3}{*}{ Correct answers $n(\%)$} & \multicolumn{3}{|c|}{ Standardized factor loadings } \\
\hline & & & & \multirow[t]{2}{*}{ One factor } & \multicolumn{2}{|c|}{ Two factors } \\
\hline & & & & & Factor 1 & Factor 2 \\
\hline Words & Portuguese & English & & & & \\
\hline METER 2 & Artrite & Arthritis & $173(88.3)$ & 0.729 & 0.847 & -0.104 \\
\hline METER 3 & Obesidade & Obesity & $183(93.4)$ & 0.849 & 0.952 & -0.105 \\
\hline METER 4 & Gripe & Flu & $195(99.5)$ & 0.893 & 0.424 & 0.758 \\
\hline METER 6 & Sífilis & Syphilis & $148(75.5)$ & 0.668 & 0.885 & -0.280 \\
\hline METER 7 & Potássio & Potassium & $161(82.1)$ & 0.746 & 0.861 & -0.108 \\
\hline METER 8 & Hormonas & Hormones & $178(90.8)$ & 0.745 & 0.819 & -0.015 \\
\hline METER 9 & Nervos & Nerves & $191(97.4)$ & 0.647 & 0.600 & 0.224 \\
\hline METER 14 & Exercício & Exercise & $176(89.8)$ & 0.650 & 0.745 & -0.015 \\
\hline METER 15 & Pústula & Pustule & $63(32.1)$ & 0.187 & 0.587 & -0.450 \\
\hline METER 17 & Rim & Kidney & $192(98.0)$ & 0.882 & 0.890 & 0.142 \\
\hline METER 18 & Urgência & Emergency & $185(94.4)$ & 0.617 & 0.633 & 0.115 \\
\hline METER 20 & Menopausa & Menopause & $192(98.0)$ & 0.769 & 0.794 & 0.146 \\
\hline METER 21 & Diagnóstico & Diagnosis & $182(92.9)$ & 0.906 & 0.947 & -0.019 \\
\hline METER 23 & Icterícia & Jaundice & $110(56.1)$ & 0.466 & 0.769 & -0.333 \\
\hline METER 24 & Bexiga & Bladder * & $191(97.4)$ & 0.907 & 0.900 & 0.131 \\
\hline METER 25 & Aborto & Miscarriage & $192(98.0)$ & 0.888 & 0.870 & 0.175 \\
\hline METER 26 & Hepatite & Hepatitis & 189 (96.4) & 0.927 & 0.945 & 0.047 \\
\hline METER 29 & Asma & Asthma & $192(98.0)$ & 0.898 & 0.897 & 0.151 \\
\hline METER 30 & Inflamatório & Inflammatory & $185(94.4)$ & 0.734 & 0.836 & -0.019 \\
\hline METER 31 & Anemia & Anemia & $190(96.9)$ & 0.880 & 0.923 & 0.054 \\
\hline METER 34 & Stress & Stress & 186 (94.9) & 0.848 & 0.906 & -0.003 \\
\hline METER 39 & Cancro & Cancer & $192(98.0)$ & 0.902 & 0.878 & 0.145 \\
\hline METER 41 & Antibióticos & Antibiotics & $191(97.4)$ & 0.870 & 0.893 & 0.104 \\
\hline METER 43 & Colite & Colitis & $116(59.2)$ & 0.225 & 0.542 & -0.306 \\
\hline METER 44 & Diabetes & Diabetes & $194(99.0)$ & 0.896 & 0.754 & 0.394 \\
\hline METER 47 & Impetigo & Impetigo & $10(5.1)$ & -0.306 & 0.059 & -0.561 \\
\hline METER 48 & Menstrual & Menstrual & $186(94.9)$ & 0.710 & 0.797 & 0.014 \\
\hline METER 50 & Convulsão & Seizure & $175(89.3)$ & 0.833 & 0.882 & -0.007 \\
\hline METER 51 & Apêndice & Appendix & $184(93.9)$ & 0.866 & 0.938 & -0.058 \\
\hline METER 54 & Dose & Dose & $166(84.7)$ & 0.754 & 0.895 & -0.187 \\
\hline METER 55 & Hemorróidas & Hemorrhoids & $161(82.1)$ & 0.303 & 0.396 & -0.017 \\
\hline METER 56 & Testículo & Testicle & 186 (94.9) & 0.931 & 0.982 & -0.065 \\
\hline METER 57 & Olho & Eye & $192(98.0)$ & 0.851 & 0.850 & 0.174 \\
\hline METER 61 & Sexualmente & Sexually & $179(91.3)$ & 0.596 & 0.674 & 0.018 \\
\hline METER 64 & Medicação & Medication ${ }^{*}$ & $191(97.4)$ & 0.731 & 0.759 & 0.131 \\
\hline METER 65 & Micróbios & Germs & $174(88.8)$ & 0.527 & 0.559 & 0.079 \\
\hline METER 66 & Gonorreia & Gonorrhea & $120(61.2)$ & 0.529 & 0.820 & -0.342 \\
\hline METER 68 & Fadiga & Fatigue & $185(94.4)$ & 0.778 & 0.841 & 0.020 \\
\hline METER 69 & Osteoporose & Osteoporosis & $186(94.9)$ & 0.642 & 0.670 & 0.102 \\
\hline METER 70 & Obstipação & Constipation & $146(74.4)$ & 0.518 & 0.742 & -0.184 \\
\hline \multicolumn{7}{|l|}{ Non-words } \\
\hline METER 1 & Imígdala & $\mathrm{N} / \mathrm{A}$ & $176(89.8)$ & 0.345 & 0.120 & 0.346 \\
\hline METER 5 & Nervosite & $\mathrm{N} / \mathrm{A}$ & $173(88.3)$ & 0.665 & 0.312 & 0.551 \\
\hline METER 10 & Anquia & $\mathrm{N} / \mathrm{A}$ & 195 (99.5) & 0.868 & 0.426 & 0.759 \\
\hline METER 11 & Cástula & $\mathrm{N} / \mathrm{A}$ & $195(99.5)$ & 0.889 & 0.426 & 0.757 \\
\hline METER 12 & Ingesto & $\mathrm{N} / \mathrm{A}$ & $173(88.3)$ & 0.345 & -0.081 & 0.581 \\
\hline METER 13 & Intestigo & $\mathrm{N} / \mathrm{A}$ & $181(92.3)$ & 0.335 & -0.023 & 0.520 \\
\hline METER 16 & Cerpes & $\mathrm{N} / \mathrm{A}$ & $194(99.0)$ & 0.650 & 0.381 & 0.565 \\
\hline METER 19 & Xirope & $\mathrm{N} / \mathrm{A}$ & $187(95.4)$ & 0.623 & 0.370 & 0.458 \\
\hline METER 22 & Candíase & $\mathrm{N} / \mathrm{A}$ & $167(85.2)$ & 0.122 & -0.298 & 0.540 \\
\hline METER 27 & Enatoma & $\mathrm{N} / \mathrm{A}$ & $185(94.4)$ & 0.575 & 0.223 & 0.552 \\
\hline METER 28 & Unhal & $\mathrm{N} / \mathrm{A}$ & $190(96.9)$ & 0.455 & 0.031 & 0.723 \\
\hline METER 32 & Linsoma & $\mathrm{N} / \mathrm{A}$ & $182(92.9)$ & 0.328 & -0.022 & 0.509 \\
\hline METER 33 & Ceresiana & $\mathrm{N} / \mathrm{A}$ & $158(80.6)$ & 0.336 & -0.014 & 0.472 \\
\hline METER 35 & Algérico & $\mathrm{N} / \mathrm{A}$ & $173(88.3)$ & 0.295 & 0.067 & 0.337 \\
\hline METER 36 & Jezum & $\mathrm{N} / \mathrm{A}$ & $166(84.7)$ & 0.393 & 0.174 & 0.345 \\
\hline METER 37 & Súrgico & $\mathrm{N} / \mathrm{A}$ & $191(97.4)$ & 0.643 & 0.440 & 0.378 \\
\hline METER 38 & Malorias & $\mathrm{N} / \mathrm{A}$ & 195 (99.5) & 0.868 & 0.426 & 0.759 \\
\hline METER 40 & Alcoolidade & $\mathrm{N} / \mathrm{A}$ & $160(81.6)$ & 0.294 & -0.107 & 0.510 \\
\hline METER 42 & Antideprimido & $\mathrm{N} / \mathrm{A}$ & $170(86.7)$ & 0.395 & -0.111 & 0.640 \\
\hline METER 45 & Otorringologista & $\mathrm{N} / \mathrm{A}$ & $138(70.4)$ & 0.221 & -0.096 & 0.374 \\
\hline METER 46 & Nósea & $\mathrm{N} / \mathrm{A}$ & $189(96.4)$ & 0.491 & 0.116 & 0.635 \\
\hline METER 49 & Gatarral & $\mathrm{N} / \mathrm{A}$ & $192(98.0)$ & 0.444 & 0.138 & 0.572 \\
\hline METER 52 & Abdominável & $\mathrm{N} / \mathrm{A}$ & $151(77.0)$ & 0.352 & -0.129 & 0.579 \\
\hline METER 53 & Enxuteca & $\mathrm{N} / \mathrm{A}$ & $192(98.0)$ & 0.589 & 0.244 & 0.622 \\
\hline METER 58 & Obstérico & $\mathrm{N} / \mathrm{A}$ & $183(93.4)$ & 0.382 & -0.205 & 0.812 \\
\hline METER 59 & Sonambulação & $\mathrm{N} / \mathrm{A}$ & $168(85.7)$ & 0.321 & -0.211 & 0.664 \\
\hline METER 60 & Drenação & $\mathrm{N} / \mathrm{A}$ & $153(78.1)$ & 0.136 & -0.323 & 0.548 \\
\hline
\end{tabular}




\begin{tabular}{|c|c|c|c|c|c|c|}
\hline & & & \multirow[t]{3}{*}{ Correct answers $n(\%)$} & \multicolumn{3}{|c|}{ Standardized factor loadings } \\
\hline & & & & \multirow[t]{2}{*}{ One factor } & \multicolumn{2}{|c|}{ Two factors } \\
\hline & & & & & Factor 1 & Factor 2 \\
\hline METER 62 & Purisia & $\mathrm{N} / \mathrm{A}$ & $193(98.5)$ & 0.594 & 0.161 & 0.762 \\
\hline METER 63 & Fibrómico & $\mathrm{N} / \mathrm{A}$ & $184(93.9)$ & 0.421 & -0.076 & 0.707 \\
\hline METER 67 & Estómico & $\mathrm{N} / \mathrm{A}$ & $185(94.4)$ & 0.571 & 0.117 & 0.700 \\
\hline \multicolumn{2}{|c|}{ Cronbach's alpha } & & & 0.894 & 0.916 & 0.828 \\
\hline
\end{tabular}

N/A: English not applicable for the non-words.

Literal translation to English instead of the original version when Portuguese words were adjusted to maintain semantic and/or structural equivalence.

recognition, in which low frequency words are less often recognized as words [25].

The instrument had a high internal consistency (Cronbach's alpha $\geq 0.80$ ) in both domains, similar to that of the original instrument (Cronbach's alpha $=0.93$ ) [10] and of other health literacy tests $[13,14]$.

The test-retest reliability was only reasonably acceptable as it is context-specific and depends on how much participants differ from each other. Even if the variability between the results in the two trials is negligible, the ICC will be small if the retest group is homogenous [26], as was the case in the group of health researchers, which is a limitation of this study.

The cut-off for the non-words could be underestimated by the Angoff method because the way it is done does not reflect the instrument's instructions, previously mentioned. It may have been hard for the judges to keep coming back to the concept that the test score default for non-words is inaction and that this corresponds to maximum score. Answering "yes/no/don't know” to the question of whether a minimally competent individual would answer the question correctly is more suitable to items with a true/false format. Despite the good performance of the final version of the instrument in discriminating the several validation groups, further studies comparing the performance of the non-word subscale with that of other health literacy tests are needed.

Different health literacy assessment instruments categorize health literacy scores into a variable number of categories in addition to providing a continuous score [27]. We decided to dichotomize the scores into adequate and inadequate instead of maintaining the three categories of the original instrument to simplify the decision-making regarding health education interventions for patients with inadequate health literacy, both in research and clinical settings.

Some validation studies of health literacy instruments have used concurrent validation, that is, through the comparison with

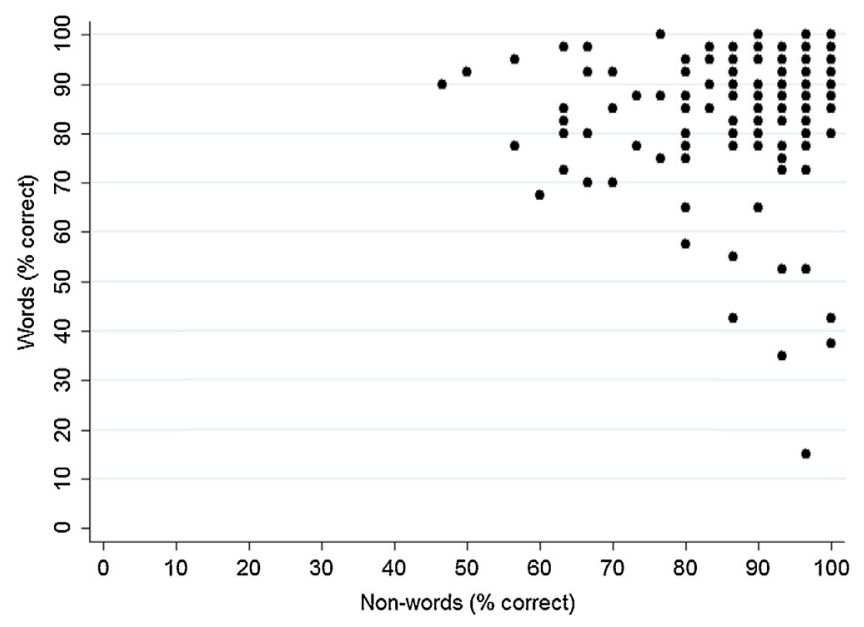

Fig. 2. Percent correct answers in words and non-words in METER. an existing instrument. This is a controversial option given the multiple proposed definitions of the underlying construct [28] and the diverse and restrictive scope of the instruments [27]. There is just no way to tell which one better represents health literacy. Our strategy assumed that health literacy should be higher in physicians, followed by health researchers, people with a similar academic degree in areas non-related to health and by people with progressively lower levels of education attainment. The data confirm this hypothesis and this suggests that the instrument measures more than educational attainment, but we cannot exclude the possibility of it not measuring more than the ability to recognize medical jargon-only one of the aspects of health literacy. Furthermore, METER and other word recognition tests do not directly address the individual ability of accessing, understanding, processing and communicating information that is included in the health literacy construct; vocabulary knowledge plays only a small part in these competencies. However, the score in these instruments is associated with other clinically relevant health measures and may be used to screen for individuals who could use more help in understanding and acting on health information. The comparison with the performance of other health literacy instruments may shed some light on this issue by exploring the need to use multiple instruments simultaneously to assess health literacy.

\subsection{Conclusion}

We culturally adapted and validated METER in the Portuguese population and defined cut-off values for adequate health literacy. This instrument distinctly differentiates individuals based on educational attainment and health-related occupation, in spite of measuring only vocabulary knowledge-a small part of the health literacy construct. Future studies should reveal how it performs when used together with health literacy instruments not based on word recognition.

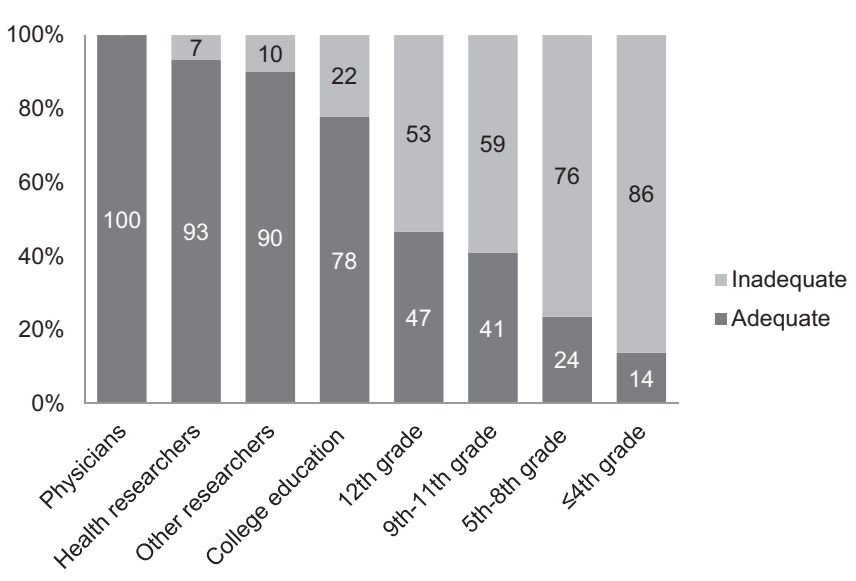

Fig. 3. Health literacy by validation group. 


\subsection{Practice implications}

The Portuguese version of METER can be used to assess health literacy in Portuguese adults and to explore associations with health outcomes. Further studies are needed to determine the usefulness of this instrument as a screening tool and decision-aid in clinical settings, either used on its own or in combination with other health literacy assessment tests.

Measuring the health literacy of Portuguese adults can highlight the issue of inadequate health literacy in the national political agenda, and raise awareness by the general population. In turn, this could indirectly promote system changes to improve the communication of health information, namely by encouraging strategies that enhance comprehension by health consumers. These strategies will benefit not only those with inadequate health literacy but potentially everybody.

\section{Acknowledgments}

We thank Teresa Oliveira, Gabriel Coutinho, Joe Pereira and Paul Charles for the translation and back-translation of the instrument. We are also grateful to each of the participants and to the institutions Faculdade de Engenharia da Universidade do Porto, Instituto de Saúde Pública da Universidade do Porto and Unidade de Saúde Familiar Monte Murado, for enabling participant recruitment.

This work was supported by Fundação para a Ciência e a Tecnologia (HMSP-IISE/SAU-ICT/0004/2009).

\section{Appendix A}

\section{Validated version of the instrument}

A lista seguinte inclui alguns termos que existem na linguagem médica. Alguns desses termos estão relacionados com partes ou funções do corpo, com tipos de doenças ou com coisas que podem melhorar ou piorar a saúde. A lista também contém algumas palavras que podem parecer ou soar como termos reais, mas que não existem.

À medida que for lendo esta lista, coloque uma cruz " $X$ " ao lado das palavras que são termos reais. Não tente adivinhar. Coloque uma cruz " $\mathrm{X}$ " ao lado das palavras só quando tiver a certeza que existem mesmo.

\begin{tabular}{ll} 
& Imígdala \\
Artrite \\
Obesidade \\
Gripe \\
\hline Nervosite \\
\hline Sífilis \\
\hline Potássio \\
\hline Hormonas \\
\hline Nervos \\
\hline Anquia \\
\hline Cástula \\
\hline Ingesto \\
\hline Intestigo \\
\hline Exercício \\
\hline Pústula \\
\hline Cerpes \\
\hline Rim \\
\hline Urgência \\
\hline Xirope \\
Menopausa \\
\hline Diagnóstico \\
\hline Candíase \\
\hline Icterícia \\
Bexiga \\
Aborto \\
Hepatite \\
Enatoma \\
\hline Unhal \\
\hline
\end{tabular}

Asma

Inflamatório

Anemia

Linsoma

Ceresiana

Stress

Algérico
Medicação

Micróbios

Gonorreia

Estómico

Fadiga

Osteoporose

Obstipação

Correct answers in boldface.

\section{References}

[1] Nielsen-Bohlman L, Panzer AM, Kindig DA, editors. Health literacy: a prescription to end confusion. Washington, D.C.: The National Academies Press; 2004

[2] Kutner M, Greenberg E, Jin Y, Paulsen C. The health literacy of America's adults: results from the 2003 National Assessment of Adult Literacy (NCES 2006-483). Washington, DC: National Center for Education Statistics; 2006.

[3] DeWalt DA, Berkman ND, Sheridan S, Lohr KN, Pignone MP. Literacy and health outcomes. J Gen Intern Med 2004;19:1228-39. Pubmed Central PMCID: PMC1492599. DOI: 10.1111/j. 1525-1497.2004.40153.x.

[4] Ad Hoc Committee on Health Literacy for the Council on Scientific Affairs. Health literacy: report of the Council on Scientific Affairs. American Medical Association. JAMA 1999;281:552-7. PubMed PMID: 10022112.

[5] Herndon JB, Chaney M, Carden D. Health literacy and emergency department outcomes: a systematic review. Ann Emerg Med 2011;57:334-45. PubMed PMID: 21035902. DOI: 10.1016/j.annemergmed.2010.08.035.

[6] Sudore RL, Yaffe K, Satterfield S, Harris TB, Mehta KM, Simonsick EM, Newman AB, Rosano C, Rooks R, Rubin SM, Ayonayon HN, Schillinger D. Limited literacy and mortality in the elderly: the health, aging, and body composition study. Gen Intern Med 2006;21:806-12. http://dx.doi.org/10.1111/j. 1525-1497. 2006.00539.x.

[7] HLS-EU Consortium. Comparative report of health literacy in eight EU member states. In: The European Health Literacy Survey HLS-EU; 2012 [cited 2013 Sep 30]. Available from 〈http://www.healthliteracy.ie/wp-content/uploads/2012/ 09/HLS-EU_report_Final_April_2012.pdf $\rangle$.

[8] Weiss BD, Mays MZ, Martz M, et al. Quick assessment of literacy in primary care: the newest vital sign. Ann Fam Med 2005;3:514-22. PubMed PMID: 16338915. DOI: $10.1370 / \mathrm{afm} .405$

[9] Plano nacional de saúde. 2012-2016: 3.1 Eixo estratégico - cidadania em saúde, [National health plan 2012-2016: 3.1 Strategic axis - health citizenship], 2012, [cited 2013 Sep 30]. Available from:(http://pns.dgs.pt/pns-em-portugues/).

[10] Rawson KA, Gunstad J, Hughes J, Spitznagel MB, Potter V, Waechter D, Rosneck J. The METER: a brief, self-administered measure of health literacy. J Gen Intern Med 2009;25:67-71. http://dx.doi.org/10.1007/s11606-009-1158-7.

[11] Davis TC, Crouch MA, Long SW, Jackson RH, Bates P, George RB, Bairnsfather LE. Rapid assessment of literacy levels of adult primary care patients. Fam Med 1991;23:433-5. PubMed PMID: 1936717.

[12] Lee S-YD, Bender DE, Ruiz RE, Cho YI. Development of an easy-to-use Spanish health literacy test. Health Serv Res 2006;41:1392-412. http://dx.doi.org 10.1111/j. 1475-6773.2006.00532.x.

[13] Hanson-Divers EC. Developing a medical achievement reading test to evaluate patient literacy skills: a preliminary study. J Health Care Poor Underserved 1997;8:56-69. PubMed PMID: 9019026.

[14] Parker RM, Baker DW, Williams MV, Nurss JR. The test of functional health literacy in adults: a new instrument for measuring patients' literacy skills. J Gen Intern Med 1995;10:537-41. PubMed PMID: 8576769.

[15] Connor M, Mantwill S, Schulz PJ. Functional health literacy in Switzerlandvalidation of a German, Italian, and French health literacy test. Patient Educ Couns 2013;90:12-7. PubMed PMID: 23089240. DOI: 10.1016/j.pec.2012. 08.018.

[16] Apolinario D, Braga RdC.O.P. Magaldi RM, Busse AL, Campora F Brucki S, Lee SYD. Short assessment of health literacy for Portuguese-speaking adults. Rev Saude Publica 2012;46:702-11. PubMed PMID: 22782124.

[17] Carthery-Goulart MT, Anghinah R, Areza-Fegyveres R, Bahia VS, Brucki SM, Damin A, Formigoni AP, Frota N, Guariglia C, Jacinto AF, Kato EM, Lima EP, Mansur L, Moreira D, Nobrega A, Porto CS, Senaha ML, Silva MN, Smid J, SouzaTalarico JN, Radanovic M, Nitrini R. Performance of a Brazilian population on the test of functional health literacy in adults. Rev Saude Publica 2009;43: 631-8. PubMed PMID: 19488667.

[18] Chang LC, Hsieh PL, Liu CH. Psychometric evaluation of the Chinese version of short-form test of functional health literacy in adolescents. J Clin Nurs 2012;21:2429-37. http://dx.doi.org/10.1111/j. 1365-2702.2012.04147.x.

[19] Baron-Epel O, Balin L, Daniely Z, Eidelman S. Validation of a Hebrew health literacy test. Patient Educ Couns 2007;67:235-9. PubMed PMID: 17386994 DOI: $10.1016 / j . p e c .2007 .02 .005$

[20] Han HR, Kim J, Kim MT, Kim KB. Measuring health literacy among immigrants with a phonetic primary language: a case of Korean American women. J Immigr Minor Health 2011;13:253-9. PubMed PMID: 20585985. Pubmed Central PMCID: PMC3010254. DOI: 10.1007/s10903-010-9366-0.

[21] Guillemin F, Bombardier C, Beaton D. Cross-cultural adaptation of healthrelated quality of life measures: literature review and proposed guidelines. Clin Epidemiol 1993;46:1417-32. PubMed PMID: 8263569.

[22] Bandaranayake RC. Setting and maintaining standards in multiple choice examinations: AMEE Guide No. 37. Med Teach 2008;30:836-45. PubMed PMID: 19117221. DOI: 10.1080/01421590802402247. 
[23] Ricker KL. Setting cut-scores: a critical review of the Angoff and modified Angoff methods. Alberta JEduc Res 2006;52:53-64. PubMed PMID: 11165581.

[24] Hu Lt Bentler PM. Cutoff criteria for fit indexes in covariance structure analysis: conventional criteria versus new alternatives. Struct Equ Modeling 1999;6:1-55. http://dx.doi.org/10.1080/10705519909540118.

[25] Grainger J, Segui J. Neighborhood frequency effects in visual word recognition: a comparison of lexical decision and masked identification latencies. Percept Psychophys 1990;47:191-8. PubMed PMID: 2304817.

[26] Weir JP. Quantifying test-retest reliability using the intraclass correlation coefficient and the SEM. J Strength Cond Res 2005;19:231-40. PubMed PMID: 15705040 .
[27] Jordan JE, Osborne RH, Buchbinder R. Critical appraisal of health literacy indices revealed variable underlying constructs, narrow content and psychometric weaknesses. J Clin Epidemiol 2011;64:366-79. PubMed PMID: 20638235. DOI: dx.doi.org/10.1016/j.jclinepi.2010.04.005.

[28] Sorensen K, Van den Broucke S, Fullam J, Doyle G, Pelikan J, Slonska Z, Brand H. Consortium Health Literacy Project E. Health literacy and public health: a systematic review and integration of definitions and models. BMC Public Health 2012;12:80. PubMed PMID: 22276600. Pubmed Central PMCID: 3292515. DOI: $10.1186 / 1471-2458-12-80$. 